\title{
Enlarged thalamic volumes and increased fractional anisotropy in the thalamic radiations in Veterans with suicide behaviors
}

\section{Melissa Lopez-Larson ${ }^{1,2,3} *$, Jace B. King ${ }^{1}$, Erin McGlade ${ }^{1,2,3}$, Elliott Bueler ${ }^{1}$, Amanda Stoeckel ${ }^{2,3}$, Daniel J. Epstein ${ }^{1}$ and Deborah Yurgelun-Todd ${ }^{1,2,3}$}

${ }^{1}$ The Brain Institute, University of Utah, Salt Lake City, UT, USA

2 University of Utah School of Medicine, Salt Lake City, UT, USA

${ }^{3}$ George E. Whalen Department of Veterans Affairs Medical Center, VA VISN 19 Mental IIIness Research, Education and Clinical Center (MIRREC), Salt Lake City, UT, USA

Edited by:

Takahiro A. Kato, Kyushu University, Japan

\section{Reviewed by:}

Christian Sorg, Klinikum Rechts der Isar Technische Universität München Germany

Niklaus Denier, University of Basel, Switzerland

\section{*Correspondence}

Melissa Lopez-Larson, The Brain Institute, 383 Colorow Drive, Salt Lake City, UT 84108, USA e-mail: melissa.lopez-larson@ hsc.utah.edu
Post-mortem studies have suggested a link between the thalamus, psychiatric disorders, and suicide. We evaluated the thalamus and anterior thalamic radiations (ATR) in a group of Veterans with and without a history of suicidal behavior (SB) to determine if thalamic abnormalities were associated with an increased risk of SB. Forty Veterans with mild traumatic brain injury (TBI) and no SB (TBI-SB), 19 Veterans with mild TBI and a history of SB $(\mathrm{TB}+\mathrm{SB})$, and 15 healthy controls $(\mathrm{HC})$ underwent magnetic resonance imaging scanning including a structural and diffusion tensor imaging scan. SBs were evaluated utilizing the Columbia Suicide Rating Scale and impulsivity was measured using the Barratt Impulsiveness Scale (BIS). Differences in thalamic volumes and ATR fractional anisotropy (FA) were examined between (1) TBI + SB versus $\mathrm{HC}$ and (2) TBI + SB versus combined $\mathrm{HC}$ and TBI$\mathrm{SB}$ and (3) between TBI $+\mathrm{SB}$ and TBI-SB. Left and right thalamic volumes were significantly increased in those with TBI + SB compared to the HC, TBI-SB, and the combined group. Veterans with TBI + SB had increased FA bilaterally compared to the HC, HC and TBI-SB group, and the TBI-SB only group. Significant positive associations were found for bilateral ATR and BIS in the TBI + SB group. Our findings of thalamic enlargement and increased FA in individuals with $\mathrm{TBI}+\mathrm{SB}$ suggest that this region may be a biomarker for suicide risk. Our findings are consistent with previous evidence indicating that suicide may be associated with behavioral disinhibition and frontal-thalamic-limbic dysfunction and suggest a neurobiologic mechanism that may increase vulnerability to suicide.

Keywords: suicide, thalamus, fractional anisotropy, MRI, veterans

\section{INTRODUCTION}

Suicide represents a major global health problem as well as a significant personal tragedy. The return of Veterans from Operation Enduring Freedom/Operation Iraqi Freedom (OEF/OIF) has emphasized the crucial importance of understanding the social, environmental, and neurobiological factors associated with suicidal behavior (SB) in both a Veteran and civilian population. However, the identification of relevant factors has often been complicated by the presence of both state and trait factors, many of which may be related to psychiatric disorders. Over the past decade, several authors have suggested that risk for suicide may be independent of a specific psychiatric disorder and may have distinct trait neurobiological expressions (1-5). For instance, biomarkers such as decreased presynaptic serotonin transporter (SERT) sites in the ventromedial prefrontal cortex (PFC) and low cerebrospinal fluid 5-hydroxyindole acetic acid have been shown to be related to suicidality and not to a specific psychiatric disorder (6-8).

Neuroimaging studies have also found regions within the fronto-striatal-limbic circuit that may be associated with SBs, irrespective of diagnosis. For example, Monkul and colleagues reported reduced orbitofrontal cortex (OFC) and increased amygdala gray matter volumes in individuals with depression and SB compared to individuals with depression alone (9). In a recent voxel-based morphometry study, 15 depressed high-risk patients, i.e., individuals who have previously attempted suicide or have a first-degree relative who attempted suicide, 15 depressed nonhigh-risk for suicide patients, and 30 matched healthy controls (HC) were evaluated (3). The authors reported that participants who were at high-risk for suicide showed significantly decreased gray matter density in fronto-striatal-limbic network brain regions in contrast to $\mathrm{HC}$, and in rostral anterior cingulate cortex (ACC) in contrast to non-high-risk patients who also suffered from major depressive disorder (MDD). In a follow-up study by the same group, cortical thickness in dorsolateral PFC, ventrolateral PFC, and ACC were reduced in the high-risk compared to the nonhigh-risk for suicide group (10). Furthermore, reduced OFC and ACC volumes have been reported in individuals with a history of suicide attempts in schizophrenic (11) and bipolar disorder (BD) (12) populations. 
Early work from Ahearn et al. (13) applied structural magnetic resonance imaging (MRI) and showed that, compared to unipolar depressed patients without a history of a suicide attempt, matched unipolar depressed patients with a previous attempt showed significantly more subcortical gray matter hyperintensities and periventricular white matter hyperintensities. These findings were consistent with those from Ehrlich and colleagues who found that patients with unipolar depression and white matter hyperintensities had a higher prevalence of suicide attempts (14). Pompili and colleagues also reported that among patients with MDD and BD (BD-I, BD-II) with and without a history of suicide attempt, those with a suicide attempt history were more likely to have white matter hyperintensities. In addition, the presence of these white matter changes increased the risk for SB by eight times $(15,16)$. These results indicate that white matter abnormalities, reflected by the presence of hyperintensities, are seen in suicidal individuals and further suggest that abnormalities in brain white matter integrity may play a role in risk for suicide. Other morphometric MRI studies of suicide have yielded findings of larger frontal white matter volume in patients with a history of a suicide attempt, which were significantly correlated with self-aggression (17). More recently Matsuo and colleagues reported that smaller anterior corpus callosum (CC) volume is highly correlated with impulsivity in suicidal patients (18) lending further support for the presence of frontal abnormalities, particularly white matter changes in individuals with SB. Taken together, these data suggest that risk factors for suicide may have separate gray and white matter neurobiological underpinnings than those alterations associated with specific psychiatric disorders $(1,3)$.

Currently there exists a paucity of conclusive findings regarding the relationship between suicide risk and traumatic brain injury (TBI). Of particular concern is the influx of TBI among Veterans returning from war zones in which they are frequently exposed to blast forces frequently resulting in disability. To date, over 320,000 soldiers have reported a possible TBI from OIF/OEF, and it has been estimated that as many as $60 \%$ of returning war Veterans have sustained a TBI $(19,20)$. In closed-head injuries, such as those suffered by soldiers exposed to blast overpressurization waves, the head is subject to forces that commonly result in shearing straining of neuronal fibers (21). This injury pattern, broadly referred to as diffuse axonal injury (DAI), seems to exert the greatest effect on structures in and around the junction between white and gray matter and most often occurs in the frontal and temporal areas, internal capsule, thalamus, and other deep gray matter structures. Conflicting reports regarding the relationship between TBI and suicide behaviors underscore the need to better understand the neuropathology of TBI and how it may affect and be affected by the risk of suicide both pre- and post-injury.

A post-mortem study of a mixed patient population, including MDD, BD, and schizophrenia, in which half died by suicide found enlarged thalamic volumes in those individuals who had an MDD diagnosis, died by suicide, or had the short allele (ss) for a genetic variant for the SERT gene (22). Individuals with the short genotype had $11 \%$ larger total thalamic volume than controls (22). Furthermore individuals with major depression had 12\% larger total thalamic volumes and individuals who had completed suicide demonstrated an $8 \%$ increase in total thalamic volume compared to controls. Authors concluded that individuals with enlarged thalami might have an anatomical vulnerability to stress deriving from alteration of thalamocortical circuitry, which may predispose individuals to symptoms of depression and to behaviors such as suicide (22). It has been shown that the SERT regulates serotonin levels in the brain by transporting serotonin from the extracellular space into the neuron. A genetic polymorphism in the promotor region of the SERT gene (5-HTTLPR) results in a short or long SERT allele. This genetic variation can alter SERT expression $(23,24)$ and the short SERT allele has been associated with an increased incidence of major depression and SB $(25,26)$. Finally, Pezawas and colleagues (27) found that normal, non-psychiatric SERT-ss carriers have a $25 \%$ reduction in the volume of the ACC and a $15 \%$ reduction in the amygdala volume. Together these findings suggest that variations in SERT affect the structure and function of fronto-thalamic-limbic systems.

The association of impulsivity, aggression, and suicide risk has been reported in the literature $(17,18,28,29)$. For example, Mann et al., reported a close association between major depression, attempted suicide, and aggression in which patients with major depression that had attempted suicide had higher overall levels of lifetime aggression and impulsivity than non-attempters (28). In addition, in a study of Veterans with mild TBI, cingulum fractional anisotropy (FA) was positively correlated with current suicidal ideation and measures of impulsivity (29). Several other neuroimaging studies have also reported volumetric and metabolic abnormalities of the PFC in aggressive, impulsive, and suicidal individuals $(9,11,17,30,31)$. Although there do not appear to be any neuroimaging studies directly implicating the thalamus, anterior limb of the internal capsule (ALIC), or anterior thalamic radiations (ATR) in aggressive and impulsive behaviors, several studies discuss the implications of thalamocortical circuitry in which thalamic projections appear to directly affect frontalexecutive functioning. For example, Mamah and colleagues (32) demonstrated a relationship between ATR fiber integrity and cognitive performance in schizophrenic patients, in which decreased anisotropy within this region correlated with decreased executive function. Coenen and colleagues used diffusion tensor imaging (DTI) fiber tracking to describe anatomical convergence of the medial forebrain bundle and ATR and suggested this convergence may sustain equilibrium between positive and negative emotions, as well as reward seeking and punishment functions evident in addictions and depression (33).

The overall aim of the proposed study was to examine the neurobiological correlates of trait related risk factors for suicide in a cohort of Veterans with TBI with and without SB, matched for depression, posttraumatic stress disorder (PTSD), and TBI severity indices. Given the recent post-mortem study of enlarged thalamic volumes in individuals who committed suicide and the paucity of data examining the morphological changes of the thalamus in individuals with SB, we performed a volumetric analysis of thalamic volumes in Veterans with TBI with and without SB. We hypothesized that individuals with SB would have enlarged thalamic volumes compared to a $\mathrm{HC}$ population and to individuals with TBI without SB. In addition, we examined the FA of the ATR to determine if FA would have a corresponding increase or decrease in association with hypothesized changes in thalamic volumes in 
our TBI with SB group. We then examined our morphological findings in relation to symptoms of impulsivity and suicide.

\section{MATERIALS AND METHODS SUBJECTS}

The Institutional Review Boards at the University of Utah and the George E. Whalen Department of Veterans Affairs (VA) Medical Center approved this study. All subjects provided written informed consent prior to participation in this study. A total of 74 male subjects including, 40 Veterans with mild TBI and no SB (TBI-SB) (age $=34.6 \pm 8.1$ years), 19 Veterans with mild TBI and a history of $\mathrm{SB}(\mathrm{TB}+\mathrm{SB})($ age $=38.0 \pm 7.8$ years $)$, and 15 $\mathrm{HC}$ (age $=36.5 \pm 11.5$ years) were recruited from the George E. Whalen VA Medical Center and the community via local advertisements and by word of mouth. Inclusion criteria for all participants in this analysis were: ages $18-55$ years old. Demographic information on the diagnostic groups is shown in Table 1. Participants were considered to have a mild TBI if they reported an injury event to the head followed by an alteration or loss of consciousness (34). The Ohio State University-TBI Identification Method (OSU-TBI) was administered during clinical evaluation to quantify presence, number, and severity of lifetime TBI injuries (35). Mild brain injury events were defined as a loss of consciousness for $30 \mathrm{~min}$ or less.

Comparison HC did not have a current major DSM-IV Axis I diagnosis, including substance use disorders (SUD) other than nicotine, based on clinical interviews. Exclusion criteria for all subjects included major sensorimotor handicaps (e.g., deafness, blindness, paralysis); estimated full scale IQ $<80$; history of claustrophobia, autism, schizophrenia, anorexia nervosa or bulimia, active medical or neurological disease other than TBI that would impact neurobiology or brain function; history of electroconvulsive therapy; and metal fragments or implants that would be contraindicated in an MRI.

\section{ASSESSMENT MEASURES}

All participants, including HC, completed the Structured Clinical Interview for DSM-IV Patient Version (SCID-I/P) (36) administered by either a board-certified psychiatrist (MLL) or a licensed clinical psychologist (ECM). Inter- and intra-rater reliability has previously been established by Dr. Lopez-Larson and Dr. Yurgelun-Todd on prior studies. However, reliability estimate for other raters, EM and AS were not performed at time of study. Therefore, all SCID evaluations and diagnoses were reviewed in collaboration with all raters (MLL, DYT, EM and AS) and consensus diagnosis/diagnoses were obtained.

Measures of current clinical status were obtained prior to scanning and included the Hamilton Depression Rating Scale (HAMD) (37) and the Hamilton Anxiety Scale (HAM-A) (38). Social status was assessed using modifications of the Hollingshead FourFactor Index of Socioeconomic Status (39). Full scale IQ was estimated using the Vocabulary subtest as it has been thought to be the

Table 1 | Demographic and clinical measures.

\begin{tabular}{|c|c|c|c|c|c|c|c|c|c|}
\hline & \multicolumn{2}{|c|}{$\begin{array}{l}\mathrm{HC} \\
(n=15)\end{array}$} & \multicolumn{2}{|c|}{$\begin{array}{l}\text { TBI-SB } \\
(n=40)\end{array}$} & \multicolumn{2}{|c|}{$\begin{array}{l}\mathrm{TBI}+\mathrm{SB} \\
(n=19)\end{array}$} & \multirow{2}{*}{$\begin{array}{c}\text { HC versus } \\
\mathrm{TBI}+\mathrm{SB} \\
p \text {-Value }\end{array}$} & \multirow{2}{*}{$\begin{array}{l}\text { TBI-SB } \\
\text { versus } \\
\text { TBI + SB } \\
p \text {-Value }\end{array}$} & \multirow{2}{*}{$\begin{array}{c}\mathrm{HC} \text { and } \mathrm{TBI}-\mathrm{SB} \\
\text { versus } \mathrm{TBI}+\mathrm{SB} \\
p \text {-Value }\end{array}$} \\
\hline & Mean & SD & Mean & SD & Mean & SD & & & \\
\hline Age & 36.47 & 11.51 & 34.60 & 8.10 & 38.00 & 7.77 & $\mathrm{~ns}$ & ns & $\mathrm{ns}$ \\
\hline GAF & 80.57 & 6.97 & 67.08 & 13.83 & 53.42 & 6.19 & $<0.001$ & $<0.001$ & $<0.001$ \\
\hline Education & 14.73 & 2.52 & 14.35 & 1.99 & 13.53 & 0.90 & 0.10 & 0.03 & 0.01 \\
\hline Hollingshead & 32.09 & 13.19 & 33.15 & 11.62 & 27.32 & 8.31 & ns & 0.06 & 0.03 \\
\hline HAM-D & 2.73 & 3.13 & 9.78 & 7.74 & 15.00 & 7.68 & $<0.001$ & 0.02 & 0.001 \\
\hline HAM-A & 3.73 & 5.16 & 13.40 & 11.65 & 14.95 & 8.13 & $<0.001$ & ns & ns \\
\hline BIS planning & 25.80 & 5.24 & 25.95 & 4.57 & 28.63 & 4.18 & 0.09 & 0.04 & 0.03 \\
\hline BIS motor & 22.73 & 4.53 & 24.13 & 5.15 & 25.47 & 5.89 & ns & ns & ns \\
\hline BIS attention & 18.87 & 2.61 & 19.25 & 3.75 & 22.00 & 3.87 & 0.01 & 0.01 & $<0.01$ \\
\hline BIS total & 67.40 & 9.19 & 69.33 & 10.43 & 76.11 & 10.83 & 0.02 & 0.03 & 0.02 \\
\hline Vocabulary & 41.27 & 7.97 & 42.88 & 7.39 & 39.79 & 9.36 & ns & ns & ns \\
\hline Age at first injury (years) & - & - & 21.49 & 6.08 & 19.37 & 6.61 & - & ns & - \\
\hline Number of mild TBI & - & - & 4.50 & 7.25 & 3.89 & 3.18 & - & ns & - \\
\hline Number of mild TBI with LOC & - & - & 0.68 & 0.83 & 1.21 & 1.03 & - & 0.04 & - \\
\hline Intensity of ideation & - & - & - & - & 17.00 & 5.26 & - & - & - \\
\hline Number of suicide attempts & - & - & - & - & 0.95 & 1.03 & - & - & - \\
\hline \multirow[t]{2}{*}{ Number of suicide behaviors } & - & - & - & - & 2.05 & 1.61 & - & - & - \\
\hline & & & $n$ & $\%$ & $n$ & $\%$ & & $x^{2}$ & \\
\hline PTSD (\%) & - & - & 23 & 57.50 & 14 & 73.68 & - & 0.26 & - \\
\hline $\operatorname{MDD}(\%)$ & - & - & 23 & 57.50 & 14 & 73.68 & - & 0.26 & - \\
\hline MDD Current (\%) & - & - & 15 & 37.50 & 7 & 36.84 & - & 0.96 & - \\
\hline Both PTSD and MDD & - & - & 16 & 40.00 & 12 & 63.16 & - & 0.10 & - \\
\hline
\end{tabular}


best estimate of general intelligence and pre-morbid level of functioning (40). The DSM-IV-TR Global Assessment of Functioning (GAF) (41) was used to assess global functioning using a scale from 1 (worst) to 100 (best). Current medications for each participant were obtained via patient interview and confirmed by chart review. Medications included in the hypnotic/non-benzodiazepine group included low dose trazodone (150 mg a day or less), prazosin, zolpidem and eszopiclone.

The Columbia Suicide Severity Rating Scale (C-SSRS) was administered to all participants to assess for the presence of past and current suicidal ideation and SB (42). In addition, the CSSRS was used to quantify the intensity of the suicidal ideation at its most severe time point in the life history of an individual and was utilized to quantify the number of SBs. SBs were defined as an actual suicide attempt, an interrupted attempt, or an aborted/self-interrupted attempt. Impulsivity was measured using the Barratt Impulsiveness Scale (BIS) (43). The BIS is a 30-item self-report questionnaire designed to assess three classes of impulsivity, including attention, motor, and non-planning categories as well as a total impulsivity score.

\section{MAGNETIC RESONANCE IMAGING}

Structural imaging was performed at the Utah Center for Advanced Imaging Research (UCAIR) using a $3 \mathrm{~T}$ Siemens Trio scanner. Structural imaging data was acquired using a T1-weighted 3D MPRAGE GRAPPA sequence acquired sagittally using a 12-channel head coil with TE/TR/TI $=3.38 \mathrm{~ms} / 2.0 \mathrm{~s} / 1.1 \mathrm{~s}$, 8 oflip, $256 \times 256$ acquisition matrix, $256 \mathrm{~mm}^{2}$ FOV, 160 slices, $1.0 \mathrm{~mm}$ slice thickness. A DT-MRI GRAPPA sequence was also obtained utilizing 64 directions, two diffusion weightings: $b=0,1000 \mathrm{~s} / \mathrm{mm}^{2}, \mathrm{TE} / \mathrm{TR}=88 \mathrm{~ms} / 9 \mathrm{~s}$; matrix $=128 \times 128$ on $256 \times 256$ on FOV; $2 \times 2 \times 2$ isotropic voxels, slice thickness $=2.0 \mathrm{~mm}$ with 0 gap, and 70 slices. The original imaging data were transferred from the scanner in the DICOM format and coded. All MRI scans were read by a neuroradiologist to rule out gross pathology.

\section{Structural MRI data}

Thalamic volumes for each participant were calculated within the FreeSurfer image analysis environment, which is documented and freely available for download online ${ }^{1}$. A description of morphometric processing tailored to the needs of this study is extracted from the written description of morphometric procedures provided at the FreeSurfer website. This processing includes motion correction, removal of non-brain tissue using a hybrid watershed/surface deformation procedure (44), automated Talairach transformation, segmentation of the subcortical white matter and deep gray matter volumetric structures $(45,46)$, intensity normalization (47), tessellation of the gray matter white matter boundary, automated topology correction $(48,49)$, and surface deformation following intensity gradients to optimally place the gray/white and gray/cerebrospinal fluid borders at the location where the greatest shift in intensity defines the transition to the other tissue class (50-52). FreeSurfer morphometric procedures have been

${ }^{1}$ http://surfer.nmr.mgh.harvard.edu/

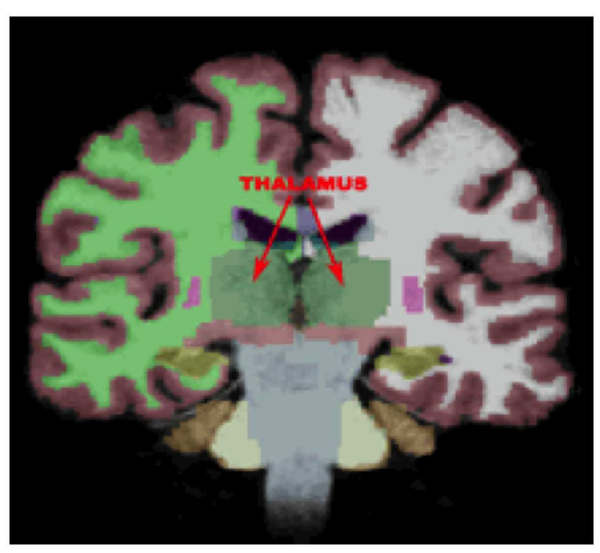

FIGURE 1 | FreeSurfer output showing left and right thalamic regions of interest.

demonstrated to show good test-retest reliability across scanner manufacturers and across field strengths (53). Quality control was performed by a trained operator (JBK) throughout MRI processing within the FreeSurfer environment via manual visual inspection of each subjects' output to ensure proper output integrity. Right and left thalamic volumetric measures were obtained from the aseg statistical output from FreeSurfer (See Figure 1).

\section{Diffusion tensor imaging}

The diffusion weighted imaging data was analyzed using FSL's FDT (FMRIB's Diffusion Toolbox, please see website for detailed methods and reference list ${ }^{2}$ ) (54-56). A description of the DTI imaging processing is extracted from the written description of the procedures provided at the FSL website. The DTI data was visually inspected for significant distortion, motion, and eddy artifact prior to processing and post-processing to ensure data integrity. Then the data was processed with tools within FDT, including eddy current and motion correction, brain extraction (57), and fitting a tensor model to the raw diffusion data. These steps resulted in extraction of FA. All subjects' FA data were then aligned into a common space using the non-linear registration tool FNIRT (58, 59 ), which uses a b-spline representation of the registration warp field (60). The target image used in the registrations was chosen to be the most "typical" subject in the study in order to generate a study specific FA target image. This target image was then affinealigned into MNI152 standard space. All participants' images were then transformed into $1 \mathrm{~mm} \times 1 \mathrm{~mm} \times 1 \mathrm{~mm}$ MNI152 space by combining the non-linear transform to the target FA image with the affine transform from that target to MNI152 space. This results in a standard-space version of each subject's FA image, which is next merged into a single FA 4D image containing all participants.

Given the study hypothesis, regions of interests (ROIs) were created for the left and right ATR utilizing the JHU white matter tractography atlas $(61,62)$. The left and right ATR ROIs were thresholded to minimum of 25 and maximum of 100 to obtain $75 \%$ probability of the ROI being within the ATR bundle (See

\footnotetext{
${ }^{2}$ http://www.fmrib.ox.ac.uk/fsl
} 


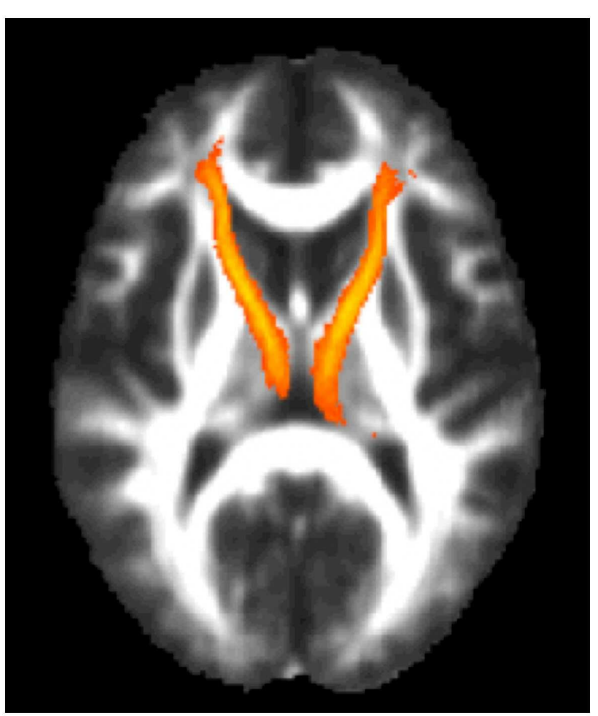

FIGURE 2 |The region of interest/mask of the bilateral anterior thalamic radiations shown in yellow-orange superimposed on the group mean fractional anisotropy image for the entire cohort. The region of interest/mask was thresholded to a $75 \%$ probability of being within the actual anterior thalamic radiations.

Figure 2). After thresholding, the left and right ATR ROIs were utilized to extract mean FA values for each participant. Next, the left and right ATR were combined and used as a white matter mask and voxel-wise group comparisons were performed via permutation testing in randomize, within FSL. The Threshold-Free Cluster Enhancement option in Randomize was used to eliminate the need to estimate a cluster-forming threshold and 5000 permutations were run for each group comparison and for each regression analysis. Test-statistical maps were produced for group and regression analyses and voxels with a $p \leq 0.01$ were considered significant. The TBSS_fill command was used within FSL to improve visualization of voxels that were significant.

\section{STATISTICS}

Statistical analyses were carried out with SPSS software (version 19) for Macintosh. Independent Student's $t$-tests and Chi-square tests were performed for demographic and clinical data. Left and right thalamic volumes extracted from FreeSurfer were evaluated first by Student's $t$-tests and then further via Univariate analyses. Thalamic volumes were adjusted by total segmented brain volume $(\mathrm{TSV})($ volume/TSV $\times 1000)$ prior to any analyses. To determine whether or not a laterality effect was present within the thalamus an asymmetry index was calculated for the thalamus using the following formula: (right volume-left volume)/[(right volume + left volume)/2]. Pearson's correlations were performed between thalamic volumes and mean FA values and clinical variables including suicide and impulsivity measures. Voxel-wise regressions were also performed via permutation testing for clinical variables and total ATR FA data. Cohen's $d$ was calculated for volumetric and mean FA data to determine effect sizes. Because we had specific a priori hypotheses regarding thalamic volumes and FA within the thalamic radiations, corrections for multiple comparisons were not performed.

\section{RESULTS}

\section{DEMOGRAPHIC AND CLINICAL MEASURES \\ Healthy controls compared to Veterans with TBI and suicide behaviors}

There were no significant between-group differences in age, years of education, vocabulary measures, or social status as assessed by the Hollingshead (39); however, a significant difference was found between groups for GAF scores (HC: $80.57 \pm 6.97$; TBI $+\mathrm{SB}$ : $53.42 \pm 6.19, p<0.001$ ) (See Table 1). Depression severity, as measured by the HAM-D, was higher in the TBI $+\mathrm{SB}$ group relative to controls (HC: $2.73 \pm 3.13$; TBI $+\mathrm{SB}: 15.00 \pm 7.68, p<0.001$ ) as was severity of anxiety symptoms, as evaluated by the HAMA (HC: $3.73 \pm 5.16$; TBI + SB: $14.95 \pm 8.13, p<0.001)$. Increased impulsivity personality traits, as assessed by the BIS total score were found in the $\mathrm{TBI}+\mathrm{SB}$ group, relative to controls (HC: $67.40 \pm 9.19 ; \mathrm{TBI}+\mathrm{SB}: 76.11 \pm 10.83, p=0.02)$ a finding that seemed to be driven by the BIS attention subscale score (HC: $18.87 \pm 2.61$; TBI + SB: $22.00 \pm 3.87, p=0.01$ ) as other subscale scores failed to reach significance.

\section{Healthy controls and Veterans with TBI and no suicide behaviors compared to Veterans with TBI and suicide behaviors}

There were no significant between-group differences in age or vocabulary measures; however, a significant difference was found between all three groups for years of education $(p=0.01)$, social status $(p=0.03)$, and GAF scores $(p<0.001)$. Depression symptom scores were higher in the TBI $+\mathrm{SB}$ group relative to the combined HC and TBI-SB group $(p<0.01)$; however, no significant difference was found between groups on HAM-A scores. A significant increase in BIS total score was found in the TBI + SB group relative to the combined group $(p=0.02)$. Subscale BIS scores assessing impulsivity traits related to attention and planning were also significantly increased in the $\mathrm{TBI}+\mathrm{SB}$ group relative to the combined group ( $p<0.01$ and $p=0.03$, respectively); however, the subscale score assessing motor impulsivity was not significantly different between groups.

\section{Veterans with TBI and no suicide behaviors compared to Veterans with TBI and suicide behaviors}

There were no significant between-group differences in age, social status, or vocabulary measures; however, a significant difference was found between groups for years of education (TBISB: $14.35 \pm 1.99, \mathrm{TBI}+\mathrm{SB}: 13.53 \pm 0.90, p=0.03)$ and $\mathrm{GAF}$ scores (TBI-SB: $67.08 \pm 13.83$, TBI + SB: $53.42 \pm 6.19, p<0.001$ ). Depression severity was higher in the $\mathrm{TBI}+\mathrm{SB}$ group relative to the TBI-SB group (TBI-SB: $9.78 \pm 7.74, \mathrm{TBI}+\mathrm{SB}$ : $15.00 \pm 7.68$, $p<0.02$ ); however, no significant difference was found between groups on HAM-A scores.

No significant difference in the overall number of TBI events was found between groups. Furthermore, there were no statistically significant differences between groups in the number of subjects diagnosed with lifetime PTSD or MDD (TBI-SB: PTSD, $n=23$ (57.5\%); MDD, $n=23$ (57.5\%); TBI + SB: PTSD, $n=14$ (73.7\%); MDD, $n=14(73.7 \%), \chi^{2}=0.26$ and 0.26 respectively), 
or both PTSD and MDD (TBI-SB: $n=16(40.0 \%)$; TBI + SB: $\left.n=12(63.2 \%), \chi^{2}=0.10\right)$. In the TBI-SB group, 10 subjects had neither a PTSD nor MDD diagnosis, 7 had PTSD only, 7 had MDD only, and 16 subjects had comorbid PTSD and MDD diagnoses. In the TBI+SB group, 3 subjects had neither a PTSD nor MDD diagnosis, 2 had PTSD only, 2 with MDD only, while 12 subjects had comorbid PTSD and MDD. In the TBI + SB only group, the number of suicide behaviors was $2.05 \pm 1.61$, number of suicide attempts was $0.95 \pm 1.03$, and intensity of ideation was $17.00 \pm 5.26$.

Of the $19 \mathrm{TBI}+\mathrm{SB}$ subjects, 13 were taking an antidepressant $(68.4 \%), 4$ were on a mood stabilizer $(21.1 \%), 7$ were taking a benzodiazepine $(36.8 \%), 3$ were on an atypical antipsychotic (15.8\%), 12 were taking a hypnotic/non-benzodiazepine (63.2\%), and 2 participants were prescribed a stimulant (10.5\%). Out of 40 TBI-SB subjects, 14 were taking an antidepressant (35.0\%), 4 were on a mood stabilizer (10.0\%), 2 were taking a benzodiazepine (5.0\%), 4 were on an atypical antipsychotic $(10.0 \%)$, 12 were taking a hypnotic/non-benzodiazepine (30.0\%), and none were prescribed a stimulant. Chi-squared analyses indicated the TBI + SB group had higher frequency of antidepressants $\left(\chi^{2}=0.02\right)$, benzodiazepines $\left(\chi^{2}=0.001\right)$, hypnotics/nonbenzodiazepines $\left(\chi^{2}=0.02\right)$, and stimulants $\left(\chi^{2}=0.04\right)$ use compared to the TB-SB group.

\section{Impact of symptoms of depression and anxiety}

Separate general linear model analyses were conducted to examine the impact of depression and anxiety, separately, using left and right adjusted thalamic volumes as the dependent variables, the appropriate groups as a fixed factor, and HAM-A and HAM$\mathrm{D}$ as covariates. Anxiety scores did not significantly impact our original findings between groups (HC vs. TBI + SB: left thalamus $p=0.006$, right thalamus, $p=0.001$; TBI-SB vs. TBI + SB: left thalamus $p=0.06$, right thalamus, $p=0.02$; HC \& TBI-SB vs. TBI + SB: left thalamus $p=0.02$, right thalamus, $p=0.01$ ). Depression scores reduced between group significance in the left thalamus between $\mathrm{HC}$ and TBI $+\mathrm{SB}$ to a trend level $(p=0.07)$, however, the remainder of the findings still maintained significance (HC vs. $\mathrm{TBI}+\mathrm{SB}$ : right thalamus, $p=0.02$; TBI-SB vs.
TBI + SB: left thalamus $p=0.04$, right thalamus, $p=0.03$; HC \& TBI-SB vs. TBI + SB: left thalamus $p=0.02$, right thalamus, $p=0.01)$.

\section{THALAMIC VOLUMES}

Thalamic volumes, adjusted for whole brain volume, for TBI $+\mathrm{SB}$ was compared to $\mathrm{HC}$, and both right $[t(1,32)=-2.10, p=0.04]$, and left $[t(1,32)=-2.78, p=0.009]$ volumes were found to be larger in the TBI + SB group. Left and right thalamic volumes were also found to be significantly larger in the TBI + SB group compared to the HC plus the TBI-SB group $[t(1,72)=-1.97$, $p=0.05$ and $t(1,72)=-2.34, p=0.02$, respectively]. When comparing TBI + SB to TBI-SB, again those with a lifetime history of SB had increased volumes in the right thalamus $[t(1,57)=-2.34$, $p=0.02]$ and demonstrated a trend in the left thalamus $[t(1$, $57)=-1.93, p=0.06]$ (See Table 2). No significant between group differences were found between HC and the combined TBI-SB and TBI + SB group in left $(p=0.53)$ or right $(p=0.62)$ adjusted thalamic volumes. No significant differences in the asymmetry index for the thalamus was found between $\mathrm{HC}$ versus $\mathrm{TBI}+\mathrm{SB}$, HC versus TBI-SB, TBI-SB versus $\mathrm{TBI}+\mathrm{SB}$, or $\mathrm{HC}$ versus $\mathrm{TBI}-\mathrm{SB}$ and $\mathrm{TBI}+\mathrm{SB}$.

\section{DIFFUSION TENSOR IMAGING}

Mean right, left, and total ATR FA values were extracted from each participant and group comparisons were performed via Student's $t$-tests. FA values were found to be higher in the TBI $+\mathrm{SB}$ group compared to the TBI-SB group on a trend level for left $\operatorname{ATR}[t(1,57)=-1.88, p=0.07]$ and total ATR $[t(1,57)=-1.83$, $p=0.07]$. No significant between group differences were found between HC and the combined TBI-SB and TBI + SB group for left $(p=0.12)$, right $(p=0.45)$, or total $(p=0.56)$ ATR FA values. No statistically significant differences were found between $\mathrm{TBI}+\mathrm{SB}$ and either HC or the combined HC and TBI-SB group (See Table 2).

Next, the left and right ATR were combined and used as a white matter mask and voxel-wise group comparisons were performed using permutation testing within FSL. Individuals with TBI + SB had increased FA in bilateral ATR when compared to the combined

Table 2 | Between-group differences comparing anterior thalamic radiations fractional anisotropy and thalamic volumes $\left(\mathrm{cm}^{3}\right.$ ) adjusted for brain segmented volume.

\begin{tabular}{|c|c|c|c|c|c|c|c|c|c|c|c|c|}
\hline & \multicolumn{2}{|c|}{$\begin{array}{l}\mathrm{HC} \\
(n=15)\end{array}$} & \multicolumn{2}{|c|}{$\begin{array}{l}\text { TBI-SB } \\
(n=40)\end{array}$} & \multicolumn{2}{|c|}{$\begin{array}{l}\text { TBI + SB } \\
(n=19)\end{array}$} & \multicolumn{2}{|c|}{$\begin{array}{l}\text { HC versus } \\
\mathrm{TBI}+\mathrm{SB}\end{array}$} & \multicolumn{2}{|c|}{$\begin{array}{l}\text { TBI-SB ver- } \\
\text { sus } \mathrm{TBI}+\mathrm{SB}\end{array}$} & \multicolumn{2}{|c|}{$\begin{array}{l}H C \text { and } T B I-S B \\
\text { versus } T B I+S B\end{array}$} \\
\hline & Mean & SD & Mean & SD & Mean & SD & $\boldsymbol{p}$ & $* d$ & $\boldsymbol{p}$ & $d$ & $\boldsymbol{p}$ & $d$ \\
\hline \multicolumn{13}{|l|}{ VOLUMES } \\
\hline Left thalamus & 6.72 & 0.41 & 6.85 & 0.47 & 7.08 & 0.33 & 0.01 & 1.01 & 0.06 & 0.54 & 0.02 & 0.65 \\
\hline Right thalamus & 7.02 & 0.39 & 7.03 & 0.46 & 7.32 & 0.43 & 0.04 & 0.75 & 0.02 & 0.65 & 0.01 & 0.67 \\
\hline Left anterior thalamic radiation & 0.40 & 0.02 & 0.39 & 0.02 & 0.41 & 0.02 & 0.66 & 0.19 & 0.07 & 0.56 & 0.12 & 0.44 \\
\hline Right anterior thalamic radiation & 0.39 & 0.02 & 0.39 & 0.02 & 0.40 & 0.02 & 0.63 & 0.21 & 0.11 & 0.51 & 0.17 & 0.41 \\
\hline Total anterior thalamic radiation & 0.40 & 0.02 & 0.39 & 0.02 & 0.40 & 0.02 & 0.63 & 0.20 & 0.07 & 0.52 & 0.12 & 0.42 \\
\hline
\end{tabular}

*Effect sizes calculated using Cohen's d. 


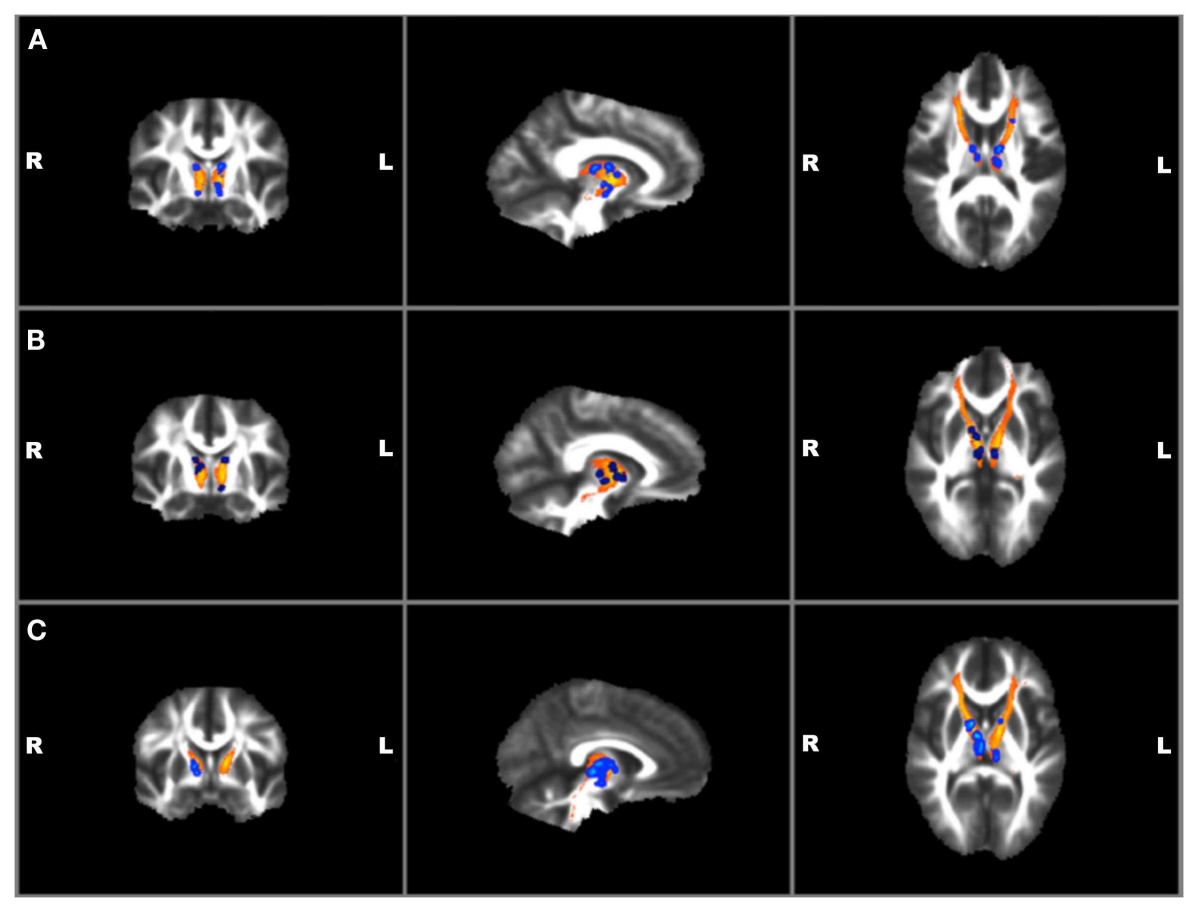

FIGURE 3 | Voxel-wise group analyses of anterior thalamic radiations with regions of significantly $(p \leq 0.01)^{*}$ increased fractional anisotropy shown in blue superimposed on the yellow-orange total (left and right) anterior thalamic radiations mask for $(A)$ individuals with $\mathrm{TBI}+\mathrm{SB}$ compared to $\mathrm{HC}$; $(B)$ individuals with $\mathrm{TBI}+\mathrm{SB}$ and the combined group of TBI-SB and $\mathrm{HC}$; $(\mathrm{C})$ individuals with $\mathrm{TBI}+\mathrm{SB}$ and TBI-SB. *Significant blue regions were filled in by TBSS_fill to improve visualization.
HC and TBI-SB group and separately with the HC and TBI-SB only groups $(p \leq 0.01)$ (See Figure 3). Additionally, a voxel-wise group analysis comparing HC and the merged all TBI found no significant between-group differences. These findings suggest that mild TBI does not appear to impact the major findings of our study.

\section{ASSOCIATIONS OF THALAMIC VOLUMES AND FRACTIONAL ANISOTROPY IN THE ANTERIOR THALAMIC RADIATIONS}

Correlations with clinical and TBI measures were performed on bilateral thalamic adjusted volumes for the TBI + SB group. In the $\mathrm{TBI}+\mathrm{SB}$ group, the right hemisphere thalamus was significantly correlated with HAM-A score $(r=-0.49, p=0.03)$. Adjusted thalamic volumes did not significantly correlate with any TBI measures. Furthermore, in the TBI + SB group, no measure of suicide or impulsivity was found to significantly correlate with adjusted thalamic volumes.

Correlations with clinical and TBI variables and mean FA values for the left and right ATR found a significant positive correlation between BIS total and RT ATR $[r(19)=0.47, p=0.04]$. No other suicide, TBI, or other clinical measures were found to correlate with mean FA values. Voxel-wise regressions were also performed via permutation testing for clinical variables and total ATR FA data. Significant positive regressions were found for bilateral ATR and HAM-A, BIS total, and BIS planning $(p \leq 0.01)$ and trends were found for bilateral ATR and HAM-D and BIS attention $(p \leq 0.05)$ (See Figure 4). Suicide measures were not found to be significantly associated with ATR. No significant correlation was found between measures of ATR FA and adjusted thalamic volumes.

\section{DISCUSSION}

To our knowledge, this is the first report of enlarged thalamic volumes in a group of male Veterans with $\mathrm{TBI}+\mathrm{SB}$ as compared to a gender, age, and diagnostically matched TBI-SB cohort and to a $\mathrm{HC}$ population. In addition, our study found that the $\mathrm{TBI}+\mathrm{SB}$ group had greater FA measures in bilateral thalamic radiations compared to both TBI-SB and HC. In the TBI + SB group, right thalamic volumes negatively correlated with HAM-A scores. Total mean FA values for the right ATR positively correlated with BIS total scores. On voxel-wise regression analysis significant positive regressions were found for bilateral ATR and HAM-A, BIS total, and BIS planning and trends were found for bilateral ATR and HAM-D and BIS attention.

The findings of enlarged thalamic volumes in our TBI $+\mathrm{SB}$ group are consistent with a post-mortem study of a mixed psychiatric patient population that also reported enlarged thalamic volumes in those individuals who died by suicide (22). Interestingly, the thalamus has one of the highest levels of SERT in the human brain (63) and the 5-HTTLPR genetic variant of SERT has been identified as a major factor influencing emotional behavior and even brain anatomy (64). Individuals with the short SERT allele had 11\% larger total thalamic volume than controls (22). Young and colleagues also reported that individuals with major depression had 12\% larger total thalamic volumes and individuals who had completed suicide demonstrated an $8 \%$ increase in total thalamic volume compared to controls (22). The SERT regulates serotonin levels in the brain by transporting serotonin from the extracellular space into the neuron, thus the altered SERT 


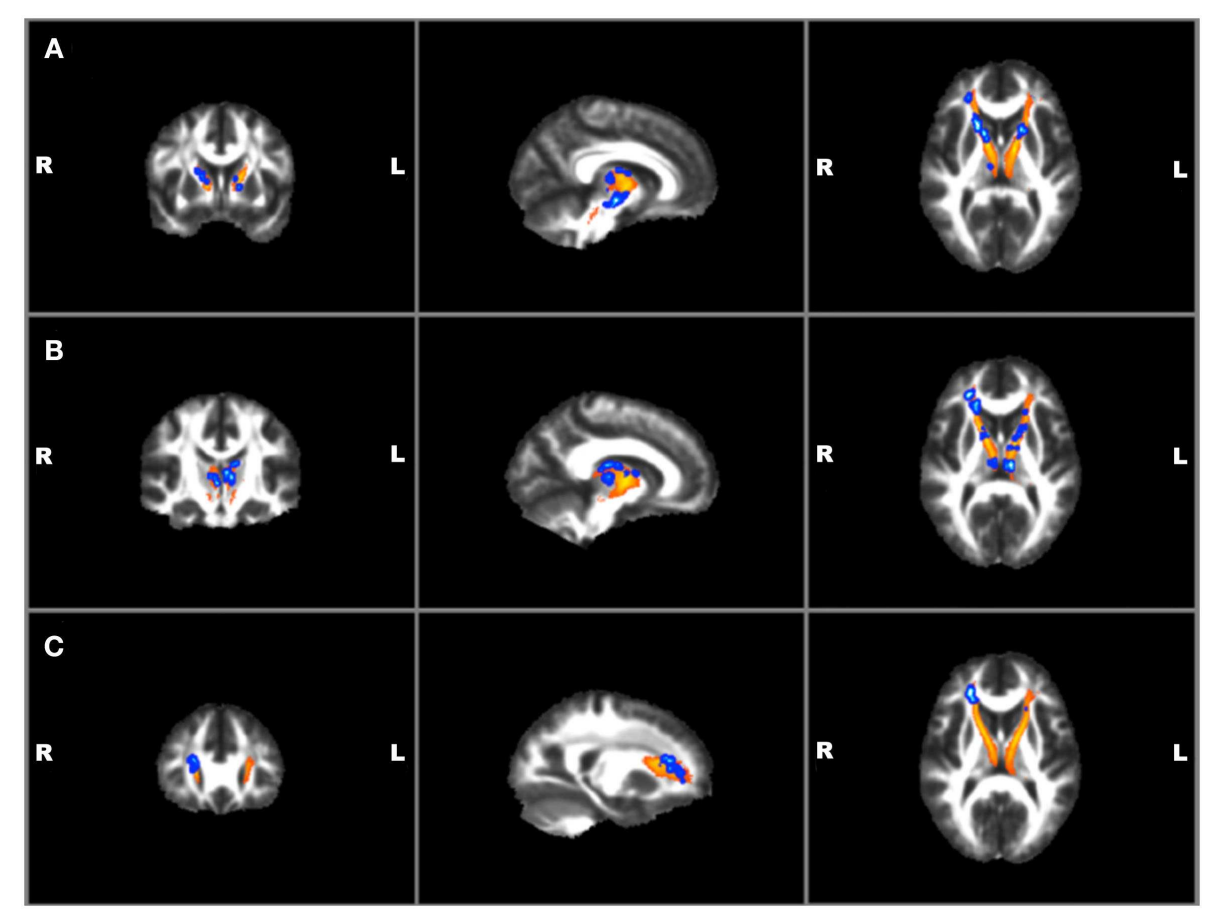

FIGURE 4 | Voxel-wise anterior thalamic regressions in TBI + SB group showing significant $(\boldsymbol{p} \leq \mathbf{0 . 0 1})^{*}$ positive regressions in blue superimposed on the yellow-orange total thalamic radiations mask for
(A) Barratt Impulsiveness Scale-Total Score; (B) Barratt Impulsiveness Scale-Planning Score; (C) Hamilton Anxiety scale. "Significant blue regions were filled in by TBSS_fill to improve visualization. expression in the short allele variation $(23,24)$ can affect serotonin availability.

The thalamus has connections with frontal and limbic structures $(65,66)$. The ALIC is the major efferent tract from the thalamus and carries two major fiber systems, including the ATR and the frontopontine tract (67). The ATR consists of fibers between the anterior thalamic nuclei and both the frontal cortex and anterior cingulate cortices. The anterior thalamic nuclei process afferent information from limbic structures (32). Thus, the thalamus is an important relay station that mediates information flow between the limbic system and the cerebral cortex (65), and thereby participates in the neural processing of cognition (executive function) $(32,68)$, and mood $(69-72)$. In support of the role of the thalamus in emotion regulation and suicide, studies have reported structural and metabolic abnormalities in the thalamus associated with depressive symptomatology (73-75) and suicide (22, 30).

The short SERT allele has been linked to limbic hyperactivity $(27,76)$, elevated levels of anxiety and depressive symptoms $(27,77)$, and an increased incidence of major depression and SB (25-27). For example, the short SERT allele has been linked to amygdala hyperactivity in $\mathrm{HC}$, suggesting that the short allele does not predict mood per se, but instead may represent a susceptibility factor for affective disorders (76). Furthermore, in a meta-analysis, Lin and colleagues (26) found no association between 5-HTTLPR polymorphism and suicide; however, among individuals with the same psychiatric diagnosis, those carrying the short allele were significantly more likely to attempt suicide. The short allele was also associated with violent suicide, but not non-violent suicide (26).
In a multimodal imaging study, Pezawas and colleagues (27) reported reduced ACC and amygdala volumes in short SERT carriers compared to individuals with the long SERT genotype. Furthermore the authors performed a functional connectivity analysis with BOLD fMRI data utilizing ACC and amygdala as ROI and noted that the short SERT allele genotype was associated with a greater functional uncoupling between these two regions compared to long SERT carriers. In addition, the functional connectivity between the amygdala and ACC was highly correlated with measures of trait anxiety (27). In contrast, Heinz and colleagues (78) reported an increase in functional coupling between amygdala and medial PFC regions in short versus long SERT carriers suggesting that the short SERT allele can have differential effects on front-limbic circuits. It is unfortunate that neither of the two studies $(27,78)$ that examined functional connectivity between frontal and limbic regions included the thalamus, given the recent study findings and post-mortem finds of enlarged thalamic nuclei in those with suicide behaviors. However, given that the short SERT genotype has been shown to influence thalamic size $(22,64)$ one can postulate that changes in fronto-limbic functional coupling in short SERT allele carriers could be related to the thalamic modulation of limbic input into frontal lobe structures.

In the current study we found the $\mathrm{TBI}+\mathrm{SB}$ group had greater FA measures in bilateral thalamic radiations compared to both TBI-SB and HC. In contrast to our study, Jia et al. (70) reported on a cohort of individuals with MDD, 16 of which were suicide attempters and 36 were not, and found suicide attempters had significantly lower FA in the white matter of the left ALIC as 
compared to $\mathrm{HC}$ and participants with MDD without a history of suicide attempts. In addition, the authors did not find evidence of altered FA (voxel-based or ROI) in bilateral hippocampus or thalamus or an association between HAM-D scores and FA (70). The differences in findings from the current study may be related to the study population (all male Veteran population versus a mixed gender civilian population), in the acquisition parameters used for the diffusion imaging protocol, and data analyses methods (whole brain voxel-wise analysis versus voxel-wise analysis of the ATR region only). Furthermore, in the current study we examined the ATR, which contains white matter fiber projections from the thalamus, through the ALIC and into the frontal cortex. Had we limited our study to the examination of the ALIC, it is possible we would have produced similar findings as Jia and colleagues. Overall, morphometric MRI studies of suicide have yielded findings of larger frontal white matter volumes (17) and high rates of white matter hyperintensities in individuals with SB (13-16, 79). These results indicate that white matter pathology may play a critical role in risk for suicide.

In the TBI + SB group, smaller thalamic volumes were associated with higher HAM-A scores, while DTI analysis found that increased bilateral FA in the ATR were associated with higher HAM-A scores. This apparent disconnect between HAM-A scores and thalamic volumes and ATR FA may be explained by the inclusion of participants with PTSD. Individuals with PTSD often exhibit high levels of anxiety, and PTSD symptoms have been associated with smaller thalamic volumes (80). Functional imaging studies have also reported reduced activation and decreased regional cerebral blood flow in the thalamus in individuals with PTSD (81-84). In addition, a recent study of functional connectivity patterns of the thalamus in individuals with PTSD found two different functional connectivity patterns between the thalamus and the frontal lobes. The authors reported that there was an increased connectivity between the thalamus and inferior and middle frontal gyri and decreased functional connectivity from the thalamus to the medial frontal gyrus and the rostral ACC (85) in individuals with PTSD relative to HC. These findings suggest that different functional fronto-thalamic circuits may be preferentially affected in PTSD. Alternatively, the differential association between HAM-A scores, thalamic volumes, and ATR FA may be due to the inclusion of individuals with TBI, as brain injury, especially DAI, seems to exert the greatest effect on structures in and around the junction between white and gray matter and most often occurs in the frontal and temporal areas, internal capsule, thalamus, and other deep gray matter structures.

In our TBI + SB group, there was a positive association between self-reported levels of impulsivity and FA in bilateral ATR regions. However, we did not find an association between suicidality and either thalamic volume or ATR FA. This could be due to the fact that the suicide measures utilized in this study may not have had enough range (number of lifetime SB) or were not the appropriate measure to detect trait (most severe intensity of ideation) behaviors. However, several other DT-MRI studies have proven effective in observing the relationship between behavioral traits and structural connectivity, particularly impulsivity and suicidality, within the brain. For example, in a study of patients with attention-deficit/hyperactivity disorder, DTI measures of frontal FA were reported to correlate with impulsivity (86). In addition, in a study of Veterans with TBI, the right cingulum FA positively correlated with current suicidal ideation and measures of impulsivity (29). Using the Stroop Task as a measure of inhibition in methamphetamine abusers, Salo and colleagues (87) reported FA values within the genu correlated significantly with measures of cognitive control. In cocaine-dependent subjects, Moeller and colleagues also reported a significant negative correlation between FA in the anterior CC and measures of impulsivity as well as a positive correlation between FA and measures of discriminability (88). Furthermore, in a recent study, Matsuo and colleagues examined the relationship between $\mathrm{CC}$ areas, impulsivity, and suicidality in participants with BD (18). The suicidal BD participants had a significant inverse correlation between anterior genu area and the BIS total, motor, and non-planning scores indicating reduced frontal volume in this regions was associated with increased impulsivity (18). Taken together these findings suggest that behavioral measures of impulsivity and suicidality are associated with frontal white matter integrity and that application of DT-MRI to detect white matter associated behavioral changes in individuals with impulsivity and suicide is informative.

There are a number of factors that must be considered when interpreting these study findings. First, the classification of TBI subjects is an area of ongoing debate and the application of different classification criteria can impact study results. Our categorization was based on subject self-report using a structured interview (OSU-TBI) (35), a method that is less sensitive than direct medical documentation. However, given that our study focused on returned Veterans and not active duty personnel, this assessment was feasible and provided an objective quantifiable method for examining Veterans with TBI. Further, our TBI sample was well characterized with current and lifetime history of psychiatric symptoms documented. In addition, our TBI groups were matched on TBI indices, lifetime PTSD, and MDD diagnosis. However, the presence of co-morbid TBI and both MDD and PTSD in our Veteran TBI groups precludes causal inferences regarding the observed findings for thalamic volumes and FA. It is also unknown what impact current and past history of medication may play in our study findings. For example, Ivanov and colleagues (89) reported that ADHD patients receiving stimulant medication demonstrated larger posterior dorsal, ventral, and anterior dorsal thalamic surfaces bilaterally compared to untreated patients. Gilbert (90) and colleagues reported both thalamic volume and symptom severity decreased significantly following 12 weeks of paroxetine treatment in individuals with obsessive-compulsive disorder. Treatment with atypical antipsychotics has also been associated with enlargement of thalamic volumes $(91,92)$. In a study of individuals with BD, those treated with lithium demonstrated a normalization of thalamic volumes as compared to individuals who did not receive lithium (93).

Thus far, reports on the effects of medication on DTI measures appear inconsistent, although some studies suggest that FA measures may be impacted by medication. For example, white matter FA has been found to be inversely related with mood stabilizer load in individuals with BD (94), antipsychotic dose positively correlated with FA in schizophrenic subjects (95) and 
antidepressant treatment has been related to significant increases in FA in subjects with obsessive-compulsive disorder (96). However, other studies have found no relationship between psychotropic medications, including antidepressants, mood stabilizers, antipsychotics, and benzodiazepines, and FA in psychiatric disorders (97-101). Additional limitations that should be considered when interpreting the findings of this study include the modest sample size, inclusion of an all male population, and the cross-sectional nature of the study.

In summary, this is one of the first studies to evaluate thalamic structural and microstructural brain changes as measured by FA using DTI and morphometry using MRI in a cohort of Veterans with TBI + SB compared to Veterans with TBI-SB and HC. The present results suggest that Veterans with $\mathrm{TBI}+\mathrm{SB}$ had enlarged thalamic volumes and increased FA in bilateral ATR as compared to both TBI-SB and HC. Furthermore, the increased FA in bilateral ATR regions was positively associated with self-reported measures of impulsivity. These findings are consistent with previous evidence indicating that suicide may be associated with behavioral

\section{REFERENCES}

1. Mann JJ. Neurobiology of suicidal behaviour. Nat Rev Neurosci (2003) 4(10):819-28. doi:10.1038/ nrn 1220

2. Ernst C, Mechawar N, Turecki G. Suicide neurobiology. Prog Neurobiol (2009) 89(4):315-33. doi:10. 1016/j.pneurobio.2009.09.001

3. Wagner G, Koch K, Schachtzabel C, Schultz CC, Sauer H, Schlosser RG. Structural brain alterations in patients with major depressive disorder and high risk for suicide: evidence for a distinct neurobiological entity? Neuroimage (2011) 54(2):1607-14. doi:10. 1016/j.neuroimage.2010.08.082

4. Brent DA, Oquendo M, Birmaher B, Greenhill L, Kolko D, Stanley $\mathrm{B}$, et al. Familial pathways to early-onset suicide attempt: risk for suicidal behavior in offspring of mood-disordered suicide attempters. Arch Gen Psychiatry (2002) 59(9):801-7. doi:10.1001/ archpsyc.59.9.801

5. Mann JJ, Apter A, Bertolote J, Beautrais A, Currier D, Haas A, et al. Suicide prevention strategies: a systematic review. JAMA (2005) 294(16):2064-74. doi:10. 1001/jama.294.16.2064

6. Arango V, Underwood MD, Gubbi AV, Mann JJ. Localized alterations in pre- and postsynaptic serotonin binding sites in the ventrolateral prefrontal cortex of suicide victims. Brain Res (1995) 688(1-2):121-33. doi:10. 1016/0006-8993(95)00523-S

7. Cooper SJ, Kelly CB, King DJ. 5-Hydroxyindoleacetic acid in cerebrospinal fluid and prediction of suicidal behaviour in schizophrenia. Lancet (1992) 340(8825):940-1. doi:10.1016/ 0140-6736(92)92819-2

8. Nordstrom P, Samuelsson M, Asberg M, Traskman-Bendz L, Aberg-Wistedt A, Nordin C, et al. CSF 5-HIAA predicts suicide risk after attempted suicide. Suicide Life Threat Behav (1994) 24(1):1-9.

9. Monkul ES, Hatch JP, Nicoletti MA, Spence S, Brambilla P, Lacerda AL, et al. Fronto-limbic brain structures in suicidal and nonsuicidal female patients with major depressive disorder. Mol Psychiatry (2007) 12(4):360-6. doi:10.1038/ sj.mp.4001919

10. Wagner G, Schultz CC, Koch K, Schachtzabel C, Sauer H, Schlosser RG. Prefrontal cortical thickness in depressed patients with high-risk for suicidal 46(11):1449-55. doi:10.1016/j. jpsychires.2012.07.013

11. Aguilar EJ, Garcia-Marti G, MartiBonmati L, Lull JJ, Moratal D, Escarti MJ, et al. Left orbitofrontal and superior temporal gyrus structural changes associated to suicidal behavior in patients with schizophrenia. Prog Neuropsychopharmacol Biol Psychiatry (2008) 32(7):1673-6. doi:10.1016/j.pnpbp.2008.06.016

12. Benedetti F, Radaelli D, Poletti S, Locatelli C, Falini A, Colombo C, et al. Opposite effects of suicidality and lithium on gray matter volumes in bipolar depression. J Affect Disord (2011) 135(1-3):139-47. doi:10.1016/j.jad.2011.07.006 behavior. J Psychiatr Res (2012)

disinhibition and frontal-thalamic-limbic dysfunction and suggest a neurobiologic mechanism that may increase vulnerability to suicide. One potential application of these findings may be identifying individuals at-risk for suicide. Further evaluation of key frontothalamic-limbic circuits via multimodal imaging combined with candidate genes for SB such as the SERT gene is warranted to ascertain whether or not individuals can be identified as "at-risk" for future suicide. In addition, examining the functional connectivity of the prefrontal-thalamic-limbic circuitry utilizing both resting state and task-based fMRI data in this population would also have the potential to expand current knowledge into the neurobiological underpinnings that may increase risk for suicide. Finally, the thalamus is a region of high susceptibility to diffuse axonal injury in TBI and therefore further study in a high risk Veteran population is needed.

\section{ACKNOWLEDGMENTS}

This work was supported by research grants from Merit review 5I01CX000253-02 and VISN 19 MIRECC, Salt Lake City, UT, USA.

13. Ahearn EP, Jamison KR, Steffens DC, Cassidy F, Provenzale JM, Lehman A, et al. MRI correlates of suicide attempt history in unipolar depression. Biol Psychiatry (2001) 50(4):266-70. doi:10.1016/S00063223(01)01098-8

14. Ehrlich S, Breeze JL, Hesdorffer DC, Noam GG, Hong X, Alban RL, et al. White matter hyperintensities and their association with suicidality in depressed young adults. $J$ Affect Disord (2005) 86(2-3):2817. doi:10.1016/j.jad.2005.01.007

15. Pompili M, Ehrlich S, De Pisa E, Mann JJ, Innamorati M, Cittadini A, et al. White matter hyperintensities and their associations with suicidality in patients with major affective disorders. Eur Arch Psychiatry Clin Neurosci (2007) 257(8):494-9. doi:10.1007/ s00406-007-0755-x

16. Pompili M, Innamorati M, Mann JJ, Oquendo MA, Lester D, Del Casale A, et al. Periventricular white matter hyperintensities as predictors of suicide attempts in bipolar disorders and unipolar depression. Prog Neuropsychopharmacol Biol Psychiatry (2008) 32(6):1501-7. doi:10.1016/ j.pnpbp.2008.05.009

17. Rusch N, Spoletini I, Wilke M, Martinotti G, Bria P, Trequattrini $A$, et al. Inferior frontal white matter volume and suicidality in schizophrenia. Psychiatry Res (2008) 164(3):206-14. doi:10.1016/j.pscychresns.2007. 12.011

18. Matsuo K, Nielsen N, Nicoletti MA, Hatch JP, Monkul ES, Watanabe Y, et al. Anterior genu corpus callosum and impulsivity in suicidal patients with bipolar disorder. Neurosci Lett (2010) 469(1):75-80. doi:10.1016/j.neulet.2009.11.047

19. Sayer NA, Chiros CE, Sigford B, Scott S, Clothier B, Pickett T, et al. Characteristics and rehabilitation outcomes among patients with blast and other injuries sustained during the global war on terror. Arch Phys Med Rehabil (2008) 89(1):163-70. doi:10.1016/j.apmr. 2007.05.025

20. Vanderploeg RD, Schwab $K$, Walker WC, Fraser JA, Sigford BJ, Date ES, et al. Rehabilitation of traumatic brain injury in active duty military personnel and veterans: defense and veterans brain injury center randomized controlled trial of two rehabilitation approaches. Arch Phys Med Rehabil (2008) 89(12):2227-38. doi:10.1016/j.apmr.2008.06.015

21. Lux WE. A neuropsychiatric perspective on traumatic brain injury. $J$ Rehabil Res Dev (2007) 44(7):951-62. doi:10.1682/JRRD.2007.01.0009

22. Young KA, Bonkale WL, Holcomb LA, Hicks PB, German DC. Major depression, 5HTTLPR genotype, suicide and antidepressant influences on thalamic volume. BrJPsychiatry (2008) 192(4):285-9. doi: 10.1192/bjp.bp.107.039180

23. Bradley SL, Dodelzon K, Sandhu HK, Philibert RA. Relationship of serotonin transporter gene polymorphisms and haplotypes to mRNA transcription. Am J Med Genet B Neuropsychiatr Genet (2005) 136B(1):58-61. doi:10.1002/ajmg.b.30185 
24. Lesch KP, Bengel D, Heils A, Sabol SZ, Greenberg BD, Petri $S$, et al. Association of anxietyrelated traits with a polymorphism in the serotonin transporter gene regulatory region. Science (1996) 274(5292):1527-31. doi:10.1126/ science.274.5292.1527

25. Hoefgen B, Schulze TG, Ohlraun $\mathrm{S}$, von Widdern $\mathrm{O}$, Hofels $\mathrm{S}$, Gross M, et al. The power of sample size and homogenous sampling: association between the 5-HTTLPR serotonin transporter polymorphism and major depressive disorder. Biol Psychiatry (2005) 57(3):247-51. doi:10.1016/ j.biopsych.2004.11.027

26. Lin P-Y, Tsai G. Association between serotonin transporter gene promoter polymorphism and suicide: results of a metaanalysis. Biol Psychiatry (2004) 55(10):1023-30. doi:10.1016/j. biopsych.2004.02.006

27. Pezawas L, Meyer-Lindenberg A, Drabant EM, Verchinski BA, Munoz KE, Kolachana BS, et al. 5HTTLPR polymorphism impacts human cingulate-amygdala interactions: a genetic susceptibility mechanism for depression. Nat Neurosci (2005) 8(6):828-34. doi:10.1038/nn1463

28. Mann JJ, Waternaux C, Haas GL, Malone KM. Toward a clinical model of suicidal behavior in psychiatric patients. Am J Psychiatry (1999) 156(2):181-9.

29. Yurgelun-Todd DA, Bueler CE, McGlade EC, Churchwell JC, Brenner LA, Lopez-Larson MP. Neuroimaging correlates of traumatic brain injury and suicidal behavior. J Head Trauma Rehabil (2011) 26(4):276-89. doi:10.1097/HTR. 0b013e31822251dc

30. Amen DG, Prunella JR, Fallon JH, Amen B, Hanks C. A comparative analysis of completed suicide using high resolution brain SPECT imaging. J Neuropsychiatry Clin Neurosci (2009) 21(4):430-9. doi:10.1176/ appi.neuropsych.21.4.430

31. Audenaert K, Goethals I, Van Laere K, Lahorte P, Brans B, Versijpt J, et al. SPECT neuropsychological activation procedure with the Verbal Fluency Test in attempted suicide patients. Nucl Med Commun (2002) 23(9):907-16. doi:10.1097/ 00006231-200209000-00015

32. Mamah D, Conturo TE, Harms MP, Akbudak E, Wang L, McMichael AR, et al. Anterior thalamic radiation integrity in schizophrenia: a diffusion-tensor imaging study. Psychiatry Res (2010) 183(2):144-50. doi:10. 1016/j.pscychresns.2010.04.013

33. Coenen VA, Panksepp J, Hurwitz $\mathrm{TA}$, Urbach $\mathrm{H}$, Madler $\mathrm{B}$. Human medial forebrain bundle (MFB) and anterior thalamic radiation (ATR): imaging of two major subcortical pathways and the dynamic balance of opposite affects in understanding depression. J Neuropsychiatry Clin Neurosci (2012) 24(2):223-36. doi:10.1176/appi.neuropsych. 11080180

34. Belanger HG, Uomoto JM, Vanderploeg RD. The Veterans Health Administration's (VHA's) Polytrauma System of Care for mild traumatic brain injury: costs, benefits, and controversies. J Head Trauma Rehabil (2009) 24(1):4-13. doi:10.1097/HTR. 0b013e3181957032

35. Corrigan JD, Bogner J. Initial reliability and validity of the Ohio State University TBI identification method. J Head Trauma Rehabil (2007) 22(6):318-29. doi:10.1097/ 01.HTR.0000300227.67748.77

36. First M, Spitzer R, Gibbon M, Williams J. Structured Clinical Interview for the DSM-IV Axis I Disorders. Washington, DC: American Psychiatric Press, Inc. (1996).

37. Hamilton M. A rating scale for depression. JNeurol Neurosurg Psychiatr (1960) 23:56-62. doi:10. 1136/jnnp.23.1.56

38. Hamilton A. Diagnosis and rating of anxiety. Br J Psychiatry (1969) 3:76-9.

39. Cirino PT, Chin CE, Sevcik RA, Wolf M, Lovett M, Morris RD. Measuring socioeconomic status: reliability and preliminary validity for different approaches. Assessment (2002) 9(2):145-55. doi:10. 1177/10791102009002005

40. Groth-Marnat G. Handbook of psychological assessment. Hoboken, NJ: John Wiley \& Sons, Inc. (2009).

41. American Psychiatric Association. Global assessment of functioning. Diagnostic and Statistical Manual of Mental Disorders: DSM-IV-TR. 4th ed. Washington, DC: American Psychiatric Association (2000). $32 \mathrm{p}$.

42. Oquendo M, Halberstam B, Mann JJ. Risk factors for suicidal behavior: utility and limitations of research instruments. In: First MB, editor. Standardized Evaluation in Clinical Practice. Washington, DC: American Psychiatric Publishing (2003). p. 103-30.
43. Patton JH, Stanford MS, Barratt ES. Factor structure of the Barratt impulsiveness scale. J Clin Psychol (1995) 51(6):768-74. doi:10.1002/10974679(199511)51:6<768::AIDJCLP2270510607>3.0.CO;2-1

44. Segonne F, Dale AM, Busa E, Glessner M, Salat D, Hahn HK, et al. A hybrid approach to the skull stripping problem in MRI. Neuroimage (2004) 22(3):1060 75. doi:10.1016/j.neuroimage. 2004.03.032

45. Fischl B, Salat DH, Busa E, Albert M, Dieterich M, Haselgrove C, et al. Whole brain segmentation: automated labeling of neuroanatomical structures in the human brain. Neuron (2002) 33(3):341-55. doi: 10.1016/S0896-6273(02)00569-X

46. Fischl B, Salat DH, van der Kouwe AJ, Makris N, Segonne F, Quinn BT, et al. Sequence-independent segmentation of magnetic resonance images. Neuroimage (2004) 23(Suppl 1):S69-84. doi:10.1016/j. neuroimage.2004.07.016

47. Sled JG, Zijdenbos AP, Evans AC. A nonparametric method for automatic correction of intensity nonuniformity in MRI data. IEEE Trans Med Imaging (1998) 17(1):87-97. doi:10.1109/42.668698

48. Segonne F, Pacheco J, Fischl B. Geometrically accurate topology-correction of cortical surfaces using nonseparating loops. IEEE Trans Med Imaging (2007) 26(4):518-29. doi:10.1109/TMI.2006.887364

49. Fischl B, Liu A, Dale AM. Automated manifold surgery: constructing geometrically accurate and topologically correct models of the human cerebral cortex. IEEE Trans Med Imaging (2001) 20(1):70-80. doi:10.1109/ 42.906426

50. Dale AM, Fischl B, Sereno MI. Cortical surface-based analysis. I. Segmentation and surface reconstruction. Neuroimage (1999) 9(2):179 94. doi:10.1006/nimg.1998.0395

51. Fischl B, Dale AM. Measuring the thickness of the human cerebral cortex from magnetic resonance images. Proc Natl Acad Sci U S A (2000) 97(20):11050-5. doi:10. 1073/pnas.200033797

52. Dale AM, Sereno MI. Improved localization of cortical activity by combining EEG, and MEG with MRI cortical surface reconstruction: a linear approach. J Cogn Neurosci (1993) 5:162-76. doi:10. 1162/jocn.1993.5.2.162
53. Han X, Jovicich J, Salat D, van der Kouwe A, Quinn B, Czanner $\mathrm{S}$, et al. Reliability of MRIderived measurements of human cerebral cortical thickness: the effects of field strength, scanner upgrade and manufacturer. $\mathrm{Neu}$ roimage (2006) 32(1):180-94. doi:10.1016/j.neuroimage.2006. 02.051

54. Woolrich MW, Jbabdi S, Patenaude B, Chappell M, Makni $\mathrm{S}$, Behrens $\mathrm{T}$, et al. Bayesian analysis of neuroimaging data in FSL. Neuroimage (2009) 45(Suppl 1):S173-86. doi:10. 1016/j.neuroimage.2008.10.055

55. Smith SM, Jenkinson M, Woolrich MW, Beckmann CF, Behrens TE, Johansen-Berg $\mathrm{H}$, et al. Advances in functional and structural MR image analysis and implementation as FSL. Neuroimage (2004) 23(Suppl 1):S208-19. doi:10.1016/i.neuroimage. 2004 . 07.051

56. Smith SM, Jenkinson M, JohansenBerg H, Rueckert D, Nichols TE, Mackay CE, et al. Tract-based spatial statistics: voxelwise analysis of multi-subject diffusion data. Neuroimage (2006) 31(4):1487505. doi:10.1016/j.neuroimage. 2006.02.024

57. Smith SM. Fast robust automated brain extraction. Hum Brain Mapp (2002) 17(3):143-55. doi:10.1002/ hbm. 10062

58. Andersson JLR, Jenkinson $M$, Smith S. Non-Linear Optimisation. (2007). FMRIB Analysis Group Technical Reports. TR07JA1. Available from: www. fmrib.ox.ac.uk/analysis/techrep.

59. Andersson JLR, Jenkinson M, Smith S. Non-Linear Registration, Aka Spatial Normalisation. (2007). FMRIB Analysis Group Technical Reports. TR07AJ2. Available from: www.fmrib.ox.ac.uk/ analysis/techrep

60. Rueckert D, Sonoda LI, Hayes C, Hill DL, Leach MO, Hawkes DJ. Nonrigid registration using freeform deformations: application to breast MR images. IEEE Trans Med Imaging (1999) 18(8):712-21. doi: $10.1109 / 42.796284$

61. Mori S, Wakana S, van Zijl PCM, Poetscher N. MRI Atlas of Human White Matter, First Edition. London: Elsevier Science (2005).

62. Wakana S, Caprihan A, Panzenboeck MM, Fallon JH, Perry M, Gollub RL, et al. Reproducibility of quantitative tractography methods applied to cerebral white matter. Neuroimage (2007) 36(3):630-44. 
doi:10.1016/j.neuroimage.2007. 02.049

63. Frankle WG, Huang Y, Hwang DR, Talbot PS, Slifstein M, Van Heertum R, et al. Comparative evaluation of serotonin transporter radioligands 11C-DASB and 11C-McN 5652 in healthy humans. $J$ Nucl Med (2004) 45(4):682-94.

64. Young KA, Holcomb LA, Bonkale WL, Hicks PB, Yazdani U, German DC. 5HTTLPR polymorphism and enlargement of the pulvinar: unlocking the backdoor to the limbic system. Biol Psychiatry (2007) 61(6):813-8. doi:10.1016/j. biopsych.2006.08.047

65. Wakana S, Jiang $H$, NagaePoetscher LM, van Zijl PC, Mori S. Fiber tract-based atlas of human white matter anatomy. Radiology (2004) 230(1):77-87. doi:10.1148/ radiol.2301021640

66. Kolb B, Whishaw IQ. Fundamentals of Human Neuropsychology. New York, NY: Worth Publishers (2003).

67. Kahle W, Frotscher M. Color Atlas and Textbook of Human Anatomy. 5th Rev. and Enlarged Ed. Vol. 1. Stuttgart: Thieme (2002). 3 p.

68. Reiman EM, Lane RD, Ahern GL, Schwartz GE, Davidson RJ, Friston KJ, et al. Neuroanatomical correlates of externally and internally generated human emotion. Am J Psychiatry (1997) 154(7):918-25.

69. Gutman DA, Holtzheimer PE, Behrens TE, Johansen-Berg H, Mayberg HS. A tractography analysis of two deep brain stimulation white matter targets for depression. Biol Psychiatry (2009) 65(4):276-82. doi:10.1016/j. biopsych.2008.09.021

70. Jia Z, Huang X, Wu Q, Zhang T, Lui S, Zhang J, et al. High-field magnetic resonance imaging of suicidality in patients with major depressive disorder. Am J Psychiatry (2010) 167(11):1381-90. doi: 10.1176/appi.ajp.2010.09101513

71. Schoene-Bake J-C, Parpaley Y, Weber B, Panksepp J, Hurwitz TA, Coenen VA. Tractographic analysis of historical lesion surgery for depression. Neuropsychopharmacology (2010) 35(13):2553-63. doi:10.1038/npp.2010.132

72. McIntosh AM, Munoz Maniega S, Lymer GK, McKirdy J, Hall J, Sussmann JE, et al. White matter tractography in bipolar disorder and schizophrenia. Biol Psychiatry (2008) 64(12):1088-92. doi: 10.1016/j.biopsych.2008.07.026

73. Drevets WC. Functional anatomical abnormalities in limbic and prefrontal cortical structures in major depression. Prog Brain Res (2000) 126:413-31. doi:10.1016/ S0079-6123(00)26027-5

74. Neumeister A, Young T, Stastny J. Implications of genetic research on the role of the serotonin in depression: emphasis on the serotonin type $1 \mathrm{~A}$ receptor and the serotonin transporter. Psychopharmacology (Berl) (2004) 174(4):512-24. doi: 10.1007/s00213-004-1950-3

75. Young KA, Holcomb LA, Yazdani U, Hicks PB, German DC. Elevated neuron number in the limbic thalamus in major depression. Am J Psychiatry (2004) 161(7):1270-7. doi:10.1176/appi.ajp.161.7.1270

76. Hariri AR, Drabant EM, Munoz KE, Kolachana BS, Mattay VS, Egan MF, et al. A susceptibility gene for affective disorders and the response of the human amygdala. Arch Gen Psychiatry (2005) 62(2):146-52. doi:10.1001/ archpsyc.62.2.146

77. Gonda X, Juhasz G, Laszik A, Rihmer Z, Bagdy G. Subthreshold depression is linked to the functional polymorphism of the 5HT transporter gene. JAffect Disord (2005) 87(2-3):291-7. doi:10. 1016/j.jad.2005.05.007

78. Heinz A, Braus DF, Smolka MN, Wrase J, Puls I, Hermann D, et al. Amygdala-prefrontal coupling depends on a genetic variation of the serotonin transporter. Nat Neurosci (2005) 8(1):20-1. doi:10. 1038/nn1366

79. Ehrlich S, Noam GG, Lyoo IK, Kwon BJ, Clark MA, Renshaw PF. White matter hyperintensities and their associations with suicidality in psychiatrically hospitalized children and adolescents. $J$ Am Acad Child Adolesc Psychiatry (2004) 43(6):770-6. doi:10.1097/ 01.chi.0000120020.48166.93

80. Shucard JL, Cox J, Shucard DW, Fetter H, Chung C, Ramasamy D, et al. Symptoms of posttraumatic stress disorder and exposure to traumatic stressors are related to brain structural volumes and behavioral measures of affective stimulus processing in police officers. Psychiatry Res (2012) 204(1):25-31. doi:10.1016/ j.pscychresns.2012.04.006

81. Bremner JD, Staib LH, Kaloupek D, Southwick SM, Soufer R, Charney DS. Neural correlates of exposure to traumatic pictures and sound in Vietnam combat veterans with and without posttraumatic stress disorder: a positron emission tomography study. Biol Psychiatry (1999)
45(7):806-16. doi:10.1016/S00063223(98)00297-2

82. Kim SJ, Lyoo IK, Lee YS, Kim J, Sim ME, Bae SJ, et al. Decreased cerebral blood flow of thalamus in PTSD patients as a strategy to reduce re-experience symptoms. Acta Psychiatr Scand (2007) 116(2):145-53. doi:10.1111/j. 1600-0447.2006.00952.x

83. Lanius RA, Williamson PC, Hopper J, Densmore M, Boksman $\mathrm{K}$, Gupta MA, et al. Recall of emotional states in posttraumatic stress disorder: an fMRI investigation. Biol Psychiatry (2003) 53(3):204-10. doi:10.1016/S00063223(02)01466-X

84. Liberzon I, Taylor SF, Fig LM, Koeppe RA. Alteration of corticothalamic perfusion ratios during a PTSD flashback. Depress Anxiety (1996) 4(3):146-50. doi:10.1002/ (SICI) 1520-6394(1996)4:3<146: :AID-DA9>3.0.CO;2-E

85. Yin $\mathrm{Y}$, Jin $\mathrm{C}, \mathrm{Hu} \mathrm{X}$, Duan $\mathrm{L}$, Li Z, Song $M$, et al. Altered resting-state functional connectivity of thalamus in earthquakeinduced posttraumatic stress disorder: a functional magnetic resonance imaging study. Brain Res (2011) 1411:98-107. doi:10.1016/ j.brainres.2011.07.016

86. Konrad A, Dielentheis TF, El Masri D, Bayerl M, Fehr C, Gesierich T, et al. Disturbed structural connectivity is related to inattention and impulsivity in adult attention deficit hyperactivity disorder. Eur J Neurosci (2010) 31(5):9129. doi:10.1111/j.1460-9568.2010. 07110.x

87. Salo R, Nordahl TE, Buonocore $\mathrm{MH}$, Natsuaki Y, Waters C, Moore $\mathrm{CD}$, et al. Cognitive control and white matter callosal microstructure in methamphetaminedependent subjects: a diffusion tensor imaging study. Biol Psychiatry (2009) 65(2):122-8. doi:10.1016/j.biopsych.2008.08. 004

88. Moeller FG, Hasan KM, Steinberg JL, Kramer LA, Dougherty DM, Santos RM, et al. Reduced anterior corpus callosum white matter integrity is related to increased impulsivity and reduced discriminability in cocaine-dependent subjects: diffusion tensor imaging. Neuropsychopharmacology (2005) 30(3):610-7. doi:10.1038/sj.npp. 1300617

89. Ivanov I, Bansal R, Hao X, Zhu $\mathrm{H}$, Kellendonk C, Miller L, et al. Morphological abnormalities of the thalamus in youths with attention deficit hyperactivity disorder. Am J Psychiatry (2010) 167(4):397-408. doi:10.1176/appi. ajp.2009.09030398

90. Gilbert AR, Moore GJ, Keshavan MS, Paulson LA, Narula V, Mac Master FP, et al. Decrease in thalamic volumes of pediatric patients with obsessivecompulsive disorder who are taking paroxetine. Arch Gen Psychiatry (2000) 57(5):449-56. doi:10.1001/archpsyc.57.5.449

91. Dazzan P, Morgan KD, Orr K, Hutchinson G, Chitnis X, Suckling $J$, et al. Different effects of typical and atypical antipsychotics on grey matter in first episode psychosis: the AESOP study. Neuropsychopharmacology (2005) 30(4):765-74. doi:10.1038/ sj.npp. 1300603

92. Strungas S, Christensen JD, Holcomb JM, Garver DL. State-related thalamic changes during antipsychotic treatment in schizophrenia: preliminary observations. Psychiatry Res (2003) 124(2):121-4. doi: 10.1016/S0925-4927(03)00092-1

93. Radenbach K, Flaig V, SchneiderAxmann T, Usher J, Reith W, Falkai P, et al. Thalamic volumes in patients with bipolar disorder. Eur Arch Psychiatry Clin Neurosci (2010) 260(8):601-7. doi:10.1007/ s00406-010-0100-7

94. Versace A, Almeida JR, Hassel S, Walsh ND, Novelli M, Klein $\mathrm{CR}$, et al. Elevated left and reduced right orbitomedial prefrontal fractional anisotropy in adults with bipolar disorder revealed by tract-based spatial statistics. Arch Gen Psychiatry (2008) 65(9):1041-52. doi:10.1001/archpsyc.65.9.1041

95. Minami T, Nobuhara K, Okugawa G, Takase K, Yoshida T, Sawada $\mathrm{S}$, et al. Diffusion tensor magnetic resonance imaging of disruption of regional white matter in schizophrenia. Neuropsychobiology (2003) 47(3):141-5. doi:10.1159/ 000070583

96. Yoo SY, Jang JH, Shin YW, Kim DJ, Park HJ, Moon WJ, et al. White matter abnormalities in drugnaive patients with obsessivecompulsive disorder: a diffusion tensor study before and after citalopram treatment. Acta Psychiatr Scand (2007) 116(3):2119. doi:10.1111/j.1600-0447.2007 01046.x

97. Barnea-Goraly N, Chang KD, Karchemskiy A, Howe ME, Reiss AL. Limbic and corpus callosum aberrations in adolescents 
with bipolar disorder: a tractbased spatial statistics analysis. Biol Psychiatry (2009) 66(3):23844. doi:10.1016/j.biopsych.2009. 02.025

98. Versace A, Almeida JR, Quevedo K, Thompson WK, Terwilliger RA, Hassel S, et al. Right orbitofrontal corticolimbic and left corticocortical white matter connectivity differentiate bipolar and unipolar depression. Biol Psychiatry (2010) 68(6):560 7. doi:10.1016/j.biopsych.2010.04. 036

99. Wessa M, Houenou J, Leboyer M, Chanraud S, Poupon C, Martinot JL, et al. Microstructural white matter changes in euthymic bipolar patients: a whole-brain diffusion tensor imaging study. Bipolar Disord (2009) 11(5):50414. doi:10.1111/j.1399-5618.2009. 00718.x

100. Yurgelun-Todd DA, Silveri MM, Gruber SA, Rohan ML, Pimentel PJ. White matter abnormalities observed in bipolar disorder: a diffusion tensor imaging study. Bipolar Disord (2007) 9(5):50412. doi:10.1111/j.1399-5618.2007. 00395.x

101. Zanetti MV, Jackowski MP, Versace A, Almeida JR, Hassel S, Duran FL, et al. State-dependent microstructural white matter changes in bipolar I depression. Eur Arch Psychiatry Clin
Neurosci (2009) 259(6):316-28. doi:10.1007/s00406-009-0002-8

Conflict of Interest Statement: The authors declare that the research was conducted in the absence of any commercial or financial relationships that could be construed as a potential conflict of interest.

Received: 14 May 2013; accepted: 25 July 2013; published online: 12 August 2013.

Citation: Lopez-Larson $M$, King $J B$, McGlade E, Bueler E, Stoeckel A, Epstein DJ and Yurgelun-Todd D (2013) Enlarged thalamic volumes and increased fractional anisotropy in the thalamic radiations in Veterans with suicide behaviors. Front. Psychiatry 4:83. doi: 10.3389/fpsyt.2013.00083

This article was submitted to Frontiers in Neuropsychiatric Imaging and Stimulation, a specialty of Frontiers in Psychiatry. Copyright (c) 2013 Lopez-Larson, King, McGlade, Bueler, Stoeckel, Epstein and Yurgelun-Todd. This is an open-access article distributed under the terms of the Creative Commons Attribution License (CC BY). The use, distribution or reproduction in other forums is permitted, provided the original author(s) or licensor are credited and that the original publication in this journal is cited, in accordance with accepted academic practice. No use, distribution or reproduction is permitted which does not comply with these terms. 